\title{
Readmission Penalties and Health Insurance Expansions: A Dispatch From Massachusetts
}

\author{
Christopher Chen, BA ${ }^{1}$, Gabriel Scheffler, $\mathrm{BA}^{2}$, Amitabh Chandra, $\mathrm{PhD}^{3 *}$
}

${ }^{1}$ School of Medicine, Washington University, St. Louis, Missouri; ${ }^{2}$ Yale Law School, New Haven, Connecticut; ${ }^{3 K e n n e d y ~ S c h o o l ~ o f ~ G o v e r n m e n t, ~}$ Harvard University, Cambridge, Massachusetts.

BACKGROUND: Payers are penalizing hospitals for high readmission rates. It is unknown whether major changes in population insurance coverage can affect readmission rates, despite the Affordable Care Act's coverage expansions coming into effect this year.

OBJECTIVE: To evaluate the impact of a large-scale insurance expansion on hospital readmissions, using Massachusetts' 2006 health reform as a natural experiment.

DESIGN: Difference-in-difference time-series design.

SETTING: All Massachusetts acute-care hospitals.

PATIENTS: Inpatient visits from 2004 to 2010.

MEASUREMENTS: Primary outcome was the hospital 30day readmission rate. Readmissions to any Massachusetts hospital were tracked.

RESULTS: Decreases in uninsurance rates during and after reform were largely limited to the hospital quartile with the highest prereform uninsurance rates (from 14\% uninsured at the start of the reform to $2.9 \%$ by the end of the study period). The other hospitals collectively experienced a smaller decline in their uninsured admissions (5.9\% at the start of reform to $2.5 \%$ by the end of the study period). According to difference-in-difference regression analysis, the highest uninsured hospital quartile experienced a modest increase in their unadjusted readmission rate of 0.6 percentage points (95\% confidence interval: $0.1 \%-1.1 \%)$ during the reform period as compared to the other hospital quartiles $(P=0.01)$. This represents a relative increase of $4.5 \%$ in the readmission rate. Risk-adjusted readmission rates showed no corresponding change.

CONCLUSIONS: The Affordable Care Act's insurance expansion may be associated with an increase in unadjusted readmission rates among hospitals that cared for disproportionate numbers of uninsured patients. Riskadjustment appears to take this effect into account. Journal of Hospital Medicine 2014;9:681-687. (C) 2014 Society of Hospital Medicine
The goal of reducing hospital readmissions has received a lot of attention in recent years, because hospital readmissions are expensive and potentially preventable. ${ }^{1}$ Medicare and some large private health insurers have instituted programs that impose penalties on hospitals with high readmission rates. ${ }^{2,3}$ However, using 30-day readmissions as a quality metric is controversial because, among other reasons, readmissions can be significantly affected by factors unrelated to hospital care quality. In particular, hospitals that care for poorer and sicker patients tend to have higher readmission rates. Payers typically risk adjust their readmission metrics to try to take into account this variation, but the adequacy of this risk adjustment is disputed. For example, the risk adjustment methodology used by the Centers for Medicare and Medicaid Services (CMS)'s Hospital Readmissions Reduction

*Address for correspondence and reprint requests: Amitabh Chandra, $\mathrm{PhD}$, Professor of Public Policy, Interfaculty Initiative in Health Policy, John F. Kennedy School of Government, Mailbox 26, 79 JFK Street, Cambridge, MA 02138; Telephone: 617-496-7356; Fax: 617-496-1722; E-mail: amitabh_chandra@harvard.edu

Additional Supporting Information may be found in the online version of this article.

Received: December 1, 2013; Revised: April 11, 2014; Accepted: April 23, 2014

2014 Society of Hospital Medicine DOI 10.1002/jhm.2213

Published online in Wiley Online Library (Wileyonlinelibrary.com).
Program does not account for patient socioeconomic status. 4

One factor that has not previously been studied to our knowledge is the relationship between hospital readmission rates and major changes in population health insurance coverage. Over the next decade, 25 million Americans are expected to gain health insurance under the Affordable Care Act (ACA). ${ }^{6}$ Across the country, hospitals vary significantly in the proportion of their patients who are uninsured. Depending on their baseline patient insurance status, some hospitals will face a major influx of newly insured patients.

The net impact of this insurance expansion on readmissions is difficult to predict, because it could in theory have various conflicting effects. Hospitals' readmission rates may increase or decrease depending on the health and socioeconomic status of the new patient populations that they serve. For instance, if hospitals face an influx of poorer and less healthy patients, then their readmission rates may go up. If, on the other hand, coverage gives previously uninsured patients the flexibility to seek care at other institutions, some hospitals may see lower readmission rates as their poorer and sicker patients seek care elsewhere. Expanding health insurance could also affect readmission rates through other channels: providing greater access to outpatient and preventive care might decrease readmissions, whereas reducing the out-of- 
pocket costs of inpatient care could increase readmissions because health care utilization tends to increase as patient cost-sharing decreases. ${ }^{7}$ Thus, there are a number of potential countervailing mechanisms and studying the impact of health insurance expansions on overall hospital readmission rates may lend us insight into patterns of patient and physician behavior. If any changes in readmission rates are not adequately accounted for by current risk-adjustment algorithms, then readmission penalties may unfairly penalize hospitals as the ACA is implemented.

The Oregon Health Insurance Experiment, which studied a population of uninsured patients who were randomly lotteried to Medicaid, provides the best empirical evidence to date about the behavior of patients who recently gain health insurance. In this study, newly insured patients were shown to have increased health care utilization across outpatient visits, prescription drugs, inpatient stays and emergency room (ER) use. The study found ambiguous results, however, regarding the relationship between patientlevel readmissions and gaining insurance coverage. ${ }^{8}$ Moreover, there was no analysis of the change in readmissions at the hospital level. Because payers track readmission rates at the hospital level, it is necessary to examine hospital, rather than individual, readmission rates to understand the consequences of applying this metric in the midst of an insurance expansion.

To evaluate the impact of a large-scale health insurance expansion on hospital-level readmission rates, we took advantage of a natural experiment in Massachusetts, which in 2006 passed a health reform law that was a model for the ACA and reduced uninsurance rates by half among working-age adults in its first year. ${ }^{9}$ We used a time-series analysis to study the relationship between the state's insurance expansion and the state's hospital readmission rates prior, during, and after their 2006 reform law. We stratified hospitals based on their percentage of patients who were uninsured prior to the reform law to determine whether the insurance expansion had a differential effect on hospitals depending on the magnitude of the change in their insured population. Given that the Oregon Health Insurance Experiment found increased utilization by patients who newly gain insurance, that previous research has shown that poorer and less healthy patients tend to have higher readmission rates, and that uninsured populations tend to be poorer and less healthy ${ }^{10}$ we hypothesized that an expansion of insurance might be associated with higher hospital readmission rates, particularly among those hospitals with the highest levels of uninsured patients prior to reform.

\section{METHODS}

We used a difference-in-difference time-series analysis that incorporated data from 2004 to 2010, 2 years before and 2 years after the 2006 to 2008 Massachusetts insurance expansion. We first obtained administrative databases from the Massachusetts government consisting of patient-level data from all hospitals in Massachusetts, reported on a quarterly basis for the fiscal year, starting on October 1. The data were collected pursuant to state regulation 114.1 CMR 17.00. Data submissions were edited, summarized, and returned to the submitting hospital by the division to verify accuracy of records. This project was exempted from institutional board review.

The first major piece of the Massachusetts health reform occurred in October 2006, when Commonwealth Care, a new set of state-subsidized private insurance plans, opened for enrollment. By January 2008, adults in Massachusetts were required to have health insurance or face financial penalties, bringing into effect the last major reform provision. As in earlier work, we defined 3 study periods based on these dates: the prereform period as before October 2006, the reform period as October 2006 through December 2007 , and the postreform period as beginning in January $2008 .^{11}$

We excluded patients 65 years or older and those younger than 18 years to focus on the demographic that benefited most from Massachusetts's insurance expansion. We first calculated each hospital's prereform insurance status according to the percentage of all inpatient stays attributed to uninsured patients at each hospital during the prereform period from January 2004 to October 2006. Based on these results, hospitals were stratified into quartiles, consistent with how the Massachusetts Center for Health Information and Analysis, the state's health care analysis agency, groups hospitals to evaluate state-wide health care trends. ${ }^{12}$ Although quartiles were used for the primary unit of analysis, all regressions were also calculated with hospital deciles as sensitivity analysis.

The primary outcome was the hospital 30-day readmission rate, calculated for each fiscal year quarter. Readmission rates were calculated as both unadjusted and risk adjusted. Risk adjustment was done using age, gender, and race as well as the Elixhauser riskadjustment scheme, a methodology that was developed by the Agency for Healthcare Research and Quality for use with administrative data. ${ }^{13}$ The Elixhauser scheme has been widely used in the peerreviewed literature to risk adjust readmission rates based on administrative data and is accepted as having good predictive validity. ${ }^{14-17}$

We tracked 30-day readmissions using each patient's unique health identification number, which counts readmissions to all hospitals in the state, not only the same hospital as the index admission. This is similar to how Medicare counts readmissions under its readmissions reduction program. We used difference-in-difference multivariate regressions to compare the change in hospital readmission rates 
TABLE 1. Prereform Patient Demographics by Hospital Quartile

\begin{tabular}{ccccc}
\hline & $\begin{array}{c}\text { Quartile 1 } \\
\text { (Lowest Uninsured } \\
\text { Hospitals) } \\
\mathrm{n}=313,917\end{array}$ & $\begin{array}{c}\text { Quartile 2, } \\
\mathrm{n}=385,256\end{array}$ & $\begin{array}{c}\text { Quartile 3, } \\
\mathrm{n}=212,948\end{array}$ & $\begin{array}{c}\text { Quartile 4 } \\
\text { (Highest Uninsured } \\
\text { Hospitals), } \\
\mathrm{n}=174,786\end{array}$ \\
\hline Age, $\mathrm{y}^{*}$ & $43.26(7.20)$ & $43.23(4.04)$ & $44.15(4.37)$ & $44.19(5.27)$ \\
$19-24, \%$ & 9.48 & 8.83 & 8.37 & 8.48 \\
$25-34, \%^{*}$ & 19.58 & 19.58 & 17.78 & 16.26 \\
$35-44, \%^{*}$ & 19.35 & 20.95 & 20.14 & 22.13 \\
$45-54, \%^{*}$ & 21.96 & 23.94 & 24.79 & 25.14 \\
$55-64, \%^{\dagger}$ & 27.72 & 25.48 & 27.84 & 27.01 \\
Male, $\%^{*}$ & $38.73(17.29)$ & $43.33(15.09)$ & $41.23(13.96)$ & $47.15(16.11)$ \\
${\text { White, } \%^{*}}^{*}$ & $81.16(22.28)$ & $78.65(22.35)$ & $74.45(24.91)$ & $73.92(24.92)$ \\
${\text { Death, } \%^{\ddagger}}^{*}$ & $1.84(5.15)$ & $0.89(.672)$ & $1.05(1.41)$ & $0.88(1.23)$ \\
Diagnosis* & $6.40(2.80)$ & $6.30(2.07)$ & $5.71(1.67)$ & $5.49(1.90)$ \\
\hline
\end{tabular}

NOTE: Standard deviation is in parentheses.

${ }^{*} P<0.001$.

${ }^{\dagger} P<0.05$.

${ }^{\ddagger} P<0.01$.

between hospital cohorts from the prereform period to the reform and postreform period, controlling for seasonality. Difference-in-difference regressions are based on linear regression models that compare the changes in the outcome variable over time of the population of interest (e.g., a hospital quartile) to that of a baseline population (e.g., comparison hospitals). The coefficients on our regression model provide an estimate of the difference between the changes of these 2 groups, thereby allowing us to estimate changes in an outcome variable among a population of interest beyond any baseline trends.

We also tested the statistical significance of changes in the readmission rate trend at the transition from the prereform to reform periods as well as reform to postreform periods, using spline regression models controlling for seasonality. Spline models construct a series of discrete, piecewise regressions (e.g., separate regressions for the prereform, reform, and postreform period), and we compared the outcomes of these regressions on readmission rates to determine whether the trend of the readmission rates differed between each time period. Spline regression models were calculated in natural $\log$ so that coefficients could be interpreted as changes in absolute percentage points (e.g., a coefficient of 0.001 is equivalent to an absolute increase in the readmission rate of 0.1 percentage points). We used a significance threshold of 0.05 using a 2-sided test. All analyses were performed using Stata version 11.2 (StataCorp, College Station, TX).

\section{RESULTS}

The prereform patient population characteristics of each hospital quartile are listed in Table 1 . Because of the large sample size, most of the demographic characteristics reached statistical significance, but not all were substantively different. Notably, the patient populations were similar by age but differed in their breakdown of race, gender, and average number of diagnostic codes. The higher uninsured hospital quartiles had more nonwhite patients and more males, as might be expected since males and minorities are more likely to be uninsured. The higher uninsured hospital quartile patients also typically tended to have fewer diagnostic codes, consistent with the possibility that they might have less access to medical attention and diagnostic testing.

Decreases in uninsurance rates during and after the reform were significantly more pronounced in the hospital quartile with the highest prereform uninsurance rates (Figure 1A). Prior to the reform, uninsured patients were concentrated into this highest uninsured hospital quartile. These hospitals saw their uninsured population drop from approximately $14 \%$ of total admissions at the start of the reform period to $5.9 \%$ by the end of the reform period, and then decrease further to $2.9 \%$ by the end of the study period. The other 3 hospital quartiles collectively experienced smaller changes in patient insurance status: uninsured patients represented about $5.9 \%$ of their collective admissions at the beginning of reform, $3.6 \%$ at the end of the reform period, and $2.5 \%$ at the end of the study period. Because changes in insurance status were most pronounced in the highest uninsured hospital quartile, these hospitals were considered the primary cohort of interest (referred to as the "highest uninsured hospital quartile").

Prior to reform, the highest uninsured hospital quartile started with a higher unadjusted readmission rate $(13.4 \%)$ than the other 3 hospital cohorts (which together had an average of $11.2 \%$ ) (Figure 1B). Rates remained steady for both groups throughout the prereform period until the beginning of reform in the fourth quarter of 2006, at which point the readmissions trend among the highest uninsured quartile had a statistically significant increase $(P<0.001$; Table 2$)$, climbing to $15 \%$ by the end of the study period. The other 3 quartiles each had no statistically significant change in their unadjusted admissions rate at the beginning of reform compared to their peers, although there was a change from the reform to postreform periods (Table 2).

The change in unadjusted readmission rates from before reform to after reform for each hospital quartile was then compared to those of their peers, using difference-in-difference regression analysis (Table 3 ). The first 2 hospital quartiles had no statistically significant change in their readmission rate from before or after reform, as compared to other hospitals, but the third quartile had a statistically significant decrease in readmissions (decrease of -0.6 percentage points $[-1.13$ to -0.01$] ; P=0.05)$, whereas the fourth and highest uninsured quartile had a statistically significant increase in their unadjusted readmission rate of 
0.6 percentage points $(P=0.01 ; 95 \%$ confidence interval: $0.1 \%-1.1 \%)$. This represented a relative decrease of $5.2 \%$ for the third quartile's readmission

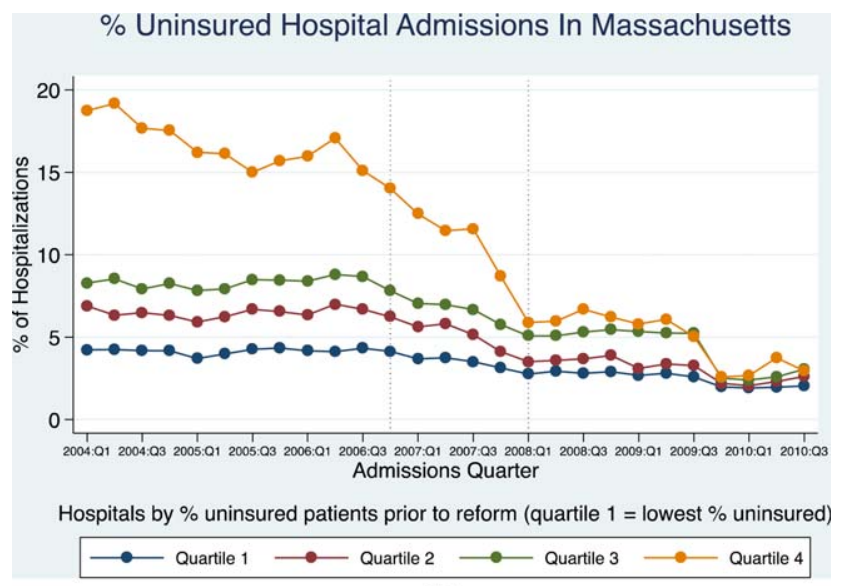

(A)

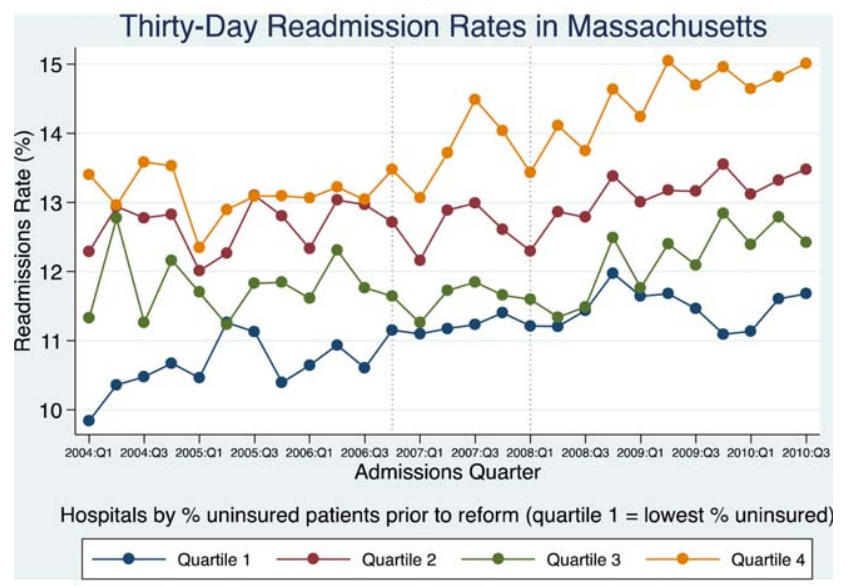

(B)

FIG. 1. Percent of uninsured hospital admissions (A) and thirty-day readmission rates $(B)$ in Massachusetts. The vertical lines indicate the prereform period as before October 2006, the reform period as October 2006 through December 2007, and the postreform period as beginning in January 2008. Between the prereform versus the reform/postreform periods, the highest uninsured hospitals had an increase in their readmission rate as compared to the control hospitals $(P=0.01$; increase of 0.6 percentage points [95\% confidence interval: $0.1 \%-1.1 \%]$ ). rate and a relative increase of $4.5 \%$ for the readmission rate of the highest uninsured quartile.

This analysis was then repeated using risk-adjusted readmission rates. In spline regression analysis, there was a statistically significant decline in readmissions for the second quartile at the start of reform $(-1.4 \%$ in absolute percentage points; standard error [SE]: $0.0058 ; P=0.0164)$, but otherwise no statistically significant change for each of the other 3 quartiles. In difference-in-difference analysis, the first quartile had an increase in its readmission rate (1.1 absolute percentage points; SE $0.26 ; P=0.0001)$, whereas the third quartile had a decrease in its readmission rate $(-0.57 \%$; SE: $0.20 ; P=0.006)$. The highest uninsured quartile had an increase in the readmission rate that approached, but did not reach, statistical significance (0.5\%; SE: $0.26 ; P=0.08)$.

For sensitivity analysis, we also stratified hospitals by deciles and repeated the regressions. The results were less precise, given the relatively small sample size in each analysis group, but were consistent with the quartile results. In difference-in-difference analysis, there was a modest, nonsignificant tendency for the higher-uninsured deciles to have small increases in their unadjusted readmission rates from the reform versus prereform period (best fit line $r^{2}=0.20$; $P=0.195$ ) (Figure 2). There was no discernable pattern in the risk-adjusted readmission rates. With spline regression models, there was no statistically significant change at the reform or postreform period for either risk-adjusted or unadjusted readmission rates for any hospital decile.

\section{DISCUSSION}

Our results support a general trend that major changes in insurance status among a hospital's patient population may be associated with increases in unadjusted readmission rates. As illustrated in Figure 1, although all hospital quartiles experienced changes in their readmission rates, the highest uninsured quartile experienced

TABLE 2. Spline Regressions Results by Hospital Quartile

\begin{tabular}{lcccc}
\hline & $\begin{array}{c}\text { Quartile 1 } \\
\text { (Lowest Uninsured Hospitals), } \\
\text { Percentage Points (SE) }\end{array}$ & $\begin{array}{c}\text { Quartile 2, } \\
\text { Percentage } \\
\text { Points (SE) }\end{array}$ & $\begin{array}{c}\text { Quartile 3 } \\
\text { Percentage } \\
\text { Points (SE) }\end{array}$ & $\begin{array}{c}\text { Quartile 4 } \\
\text { (Highest Uninsured Hospitals), } \\
\text { Percentage Points (SE) }\end{array}$ \\
\hline $\begin{array}{c}\text { Change in readmission rate in absolute percentage points from prereform } \\
\text { to reform period (unadjusted) }\end{array}$ & $+0.74 \%(0.36)$ & $+0.048 \%(0.24)$ & $-0.24 \%(0.44)$ & $+1.3 \%(0.0032)^{*}$ \\
$\begin{array}{c}\text { Change in readmission rate in absolute percentage points from prereform } \\
\text { to reform period (adjusted) }\end{array}$ & $-0.13 \%(1.3)$ & $-1.4 \%(0.58)^{\dagger}$ & $-0.40 \%(0.88)$ & $+0.52 \%(1.2)$ \\
$\begin{array}{c}\text { Change in readmission rate in absolute percentage points from reform } \\
\text { to postreform period (unadjusted) }\end{array}$ & $+0.050 \%(0.16)$ & $+0.58 \%(0.12)^{\ddagger}$ & $+1.0 \%(0.21)^{\ddagger}$ & $+0.69 \%(0.20)^{*}$ \\
$\begin{array}{l}\text { Change in readmission rate in absolute percentage points from reform } \\
\text { to postreform period (adjusted) }\end{array}$ & $-0.55 \%(0.58)$ & $-0.62 \%(0.32)$ & $+0.18 \%(0.39)$ & $-0.54 \%(0.65)$ \\
\hline
\end{tabular}

\footnotetext{
NOTE: Abbreviations: SE, standard error. 
TABLE 3. Difference-in-Difference Analysis by Hospital Quartile

\begin{tabular}{|c|c|c|c|c|}
\hline & $\begin{array}{c}\text { Quartile 1 } \\
\text { (Lowest Uninsured Hospitals), } \\
\text { Percentage Points (SE) }\end{array}$ & $\begin{array}{l}\text { Quartile 2, } \\
\text { Percentage } \\
\text { Points (SE) }\end{array}$ & $\begin{array}{l}\text { Quartile 3, } \\
\text { Percentage } \\
\text { Points (SE) }\end{array}$ & $\begin{array}{c}\text { Quartile 4 } \\
\text { (Highest Uninsured Hospitals), } \\
\text { Percentage Points (SE) }\end{array}$ \\
\hline Change in readmission rate in absolute percentage points (adjusted) & $+1.099 \%(0.263)^{*}$ & $-0.096 \%(0.197)$ & $-0.567 \%(0.198)^{\dagger}$ & $+0.461 \%(0.260)$ \\
\hline Change in readmission rate in absolute percentage points (unadjusted) & $+0.145 \%(0.196)$ & $-0.428 \%(0.267)$ & $-0.572 \%(0.282)^{\ddagger}$ & $+0.604 \%(0.232)^{\ddagger}$ \\
\hline
\end{tabular}

NOTE: Abbreviations: SE, standard error.

${ }^{*} P<0.001$.

${ }^{\dagger} P<0.01$.

${ }^{\ddagger} P<0.05$.

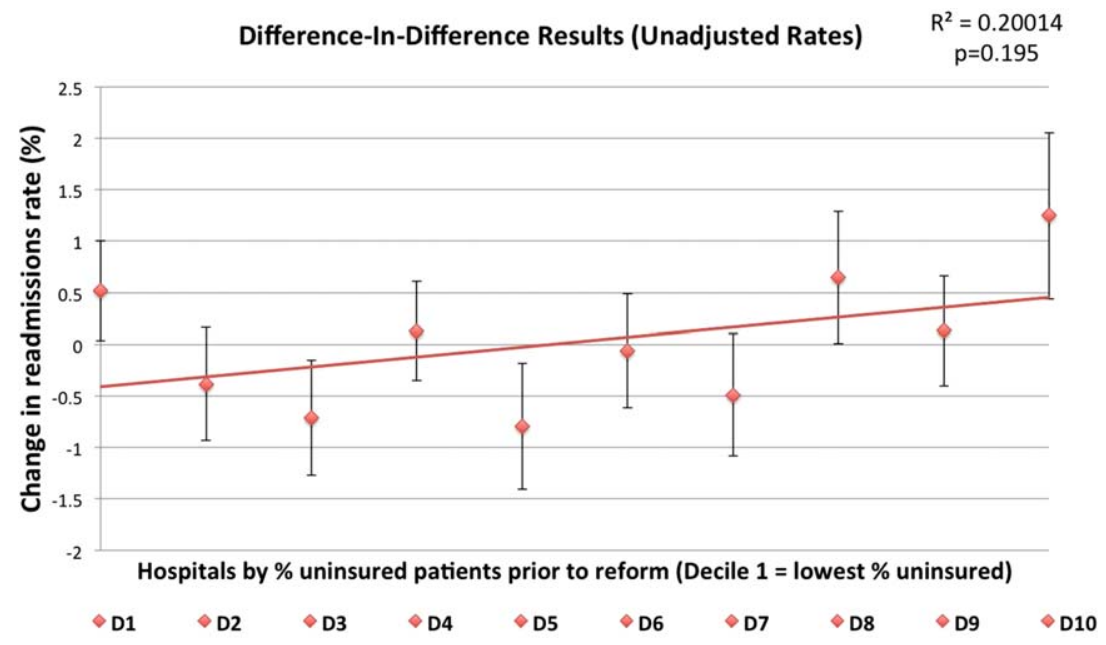

FIG. 2. Sensitivity analysis: difference-in-difference regression results by hospital decile. Decile 1 (D1) represents the lowest uninsured hospitals, and decile 10 (D10) represents the highest uninsured hospitals.

a change in insurance status of much greater magnitude from the reform to postreform period. This highest uninsured hospital quartile had a significant increase in its readmission rate compared to its peers from the prereform to the reform and postreform period, whereas the other 3 hospital quartiles had no change in their readmission rate. When the readmission rate was risk adjusted, there was no clear relationship between uninsurance status and changes in readmission rate.

There are a few different mechanisms that could explain why health insurance expansions may be associated with increased hospital readmissions. First, the Oregon Health Insurance Experiment found that patients who newly gain insurance were more likely to use health care resources across the board-outpatient, prescribing drugs, inpatient care, and ER use. ${ }^{8}$ Because health insurance reduces the out-of-pocket cost of a hospital readmission, just as with other types of health care (ER use, outpatient use), patients may be more willing to return to the hospital after they have been released. Second, increased readmissions among high-uninsured hospitals could be driven not by the insurance expansion but by cuts to safety-net hospital funding that were part of the Massachusetts reform law. The law cut block payments to safety-net hospitals in anticipation of the expanded insurance coverage being sufficient to cover their costs, which has not necessarily proven to be the case. For example, Boston Medical Center, one of Boston's most prominent safety-net hospitals, found itself in such financial straits after the passage of the health reform law that it sued the state Medicaid program for supplemental reimbursement. ${ }^{18}$ These funding cuts may have affected the ability of safety-net hospitals to invest in care coordination resources or care quality, which could affect readmission rates. The ACA makes similar cuts to federal funding for safety-net hospitals. ${ }^{19}$

Finally, the increase in unadjusted rates could be due to the fact that the insurance expansion resulted in an influx of sicker and poorer patients. Previous research shows that socioeconomic and health status are major factors driving readmissions, with economically disadvantaged individuals and individuals with severe medical conditions subject to a greater risk of being readmitted. ${ }^{10}$ By expanding insurance coverage to a poorer, sicker population, the Massachusetts law may have resulted in the state's population of insured patients becoming, on average, more likely to be readmitted. All four hospital quartiles experienced increases in the average number of diagnoses per 
patient, as time went on ranging from +0.12 to +1.34 , although at least part of this increase is likely due to patients getting better access to diagnostic testing after the reform law. This would also explain why unadjusted readmission rates increased, but riskadjusted rates which control for patient comorbidities, did not exhibit a similar increase. If true, this would suggest that, hospitals that previously took care of significant uninsured populations may face sicker patients after reform.

Our study has several limitations. Our analysis is a nonrandomized design and cannot prove causality, so it is possible that exogenous trends, such as changes in the economy, may have influenced the results. In addition, our results are drawn from a single state and so may not be generalizable to the national experience under the ACA. Because our study was at the hospital level, we could not determine whether the observed changes are due to changes at the hospital level (e.g., a change in the patient population of hospitals) or to changes in the behavior of individuals. Another concern is ascertainment bias: uninsured patients may be less likely to be accurately tracked across the health care system and marked as readmitted, so nominally greater readmission rates post-reform may simply be due to more accurate record-keeping.

We cannot definitively rule out this last possibility. However, there are several reasons to think it is not driving our results. First, Massachusetts's state reporting system is robust; hospitals are legally required to report timely and accurate data, and the state agency conducts a quality-control process that rejects each hospital's data submission if it exceeds a $1 \%$ error rate. ${ }^{20}$ Second, the fact that risk-adjusted readmission rates do not increase post-reform casts doubt on this hypothesis.

The divergence between the unadjusted readmission rates and the risk-adjusted rates reinforces the importance of the risk-adjustment algorithms used by CMS and endorsed by the National Quality Forum. ${ }^{21}$ Our finding that the risk-adjusted readmission rates exhibited no significant increase may allay concerns that using readmission rates as a quality metric will unfairly penalize some hospitals for changes driven by expanded insurance coverage under the ACA (though our results have no bearing on other criticisms of hospital readmission penalties, for example, that these penalties unfairly penalize hospitals for patient socioeconomic status). Because Medicare and private payers' readmissions programs use risk-adjusted rates, an influx of sicker patients postreform should not result in and of itself in increased readmissions penalties.

The insurance expansions of the ACA are similar in time frame and mechanism but greater in magnitude than the Massachusetts law. ${ }^{6}$ Thus, the Massachusetts experience suggests that as the country goes through ACA's major insurance expansion, facilities that cared disproportionately for uninsured patients prior to the expansion may experience similar increases in readmissions, and that risk adjustment is necessary to prevent these hospitals from being penalized unfairly. However, although risk adjustment may ensure that insurers' readmissions programs do not unfairly penalize those hospitals that care for disproportionate numbers of the previously uninsured, these hospitals should still be prepared for a potential increase in their raw number of readmissions. The Medicare readmissions program penalizes hospitals for high readmission rates among each hospital's Medicare patients, meaning that an increase in readmissions for a hospital's non-Medicare population would not trigger greater Medicare penalties. ${ }^{9}$ Nevertheless, the general hospital 30-day readmission rate is widely used as a quality metric and has been endorsed as such by the National Quality Forum.'

To our knowledge, this is the first study of the effect of a major insurance expansion on readmission rates. More research, using multistate analysis, is needed to validate these findings and to determine the mechanism by which insurance expansions increase hospital readmissions. As policymakers and payers design and implement programs that tie financial penalties to quality indicators such as Medicare's valuebased purchasing program, they should be mindful that the ACA's insurance expansion may influence hospital outcomes in unexpected ways.

Disclosures: Amitabh Chandra was supported by grant P01 AG1978302 from the National Institute on Aging. The National Institute on Aging had no role in the design and conduct of the study; collection, management, analysis, and interpretation of the data; and preparation, review, or approval of the manuscript. Data for this analysis come from the Massachusetts Division of Health Care Finance and Policy. The analyses, conclusions, interpretations, and recommendations in this article are solely those of the authors and should not be attributed to this agency.

\section{References}

1. Joynt KE, Jha AK. Thirty-day readmissions-truth and consequences. N Engl J Med. 2012;366(15):1366-1369.

2. United HealthCare Community \& State Payment Policy Committee. Readmission Policy. Available at: https://www.unitedhealthcare online.com/ccmcontent/ProviderII/UHC/en-US/Assets/ProviderStatic Files/ProviderStaticFilesPdf/Tools\%20and\%20Resources/Policies\%20 and\%20Protocols/Medical\%20Policies/Medical\%20Policies/Hospital_ Readmissions.pdf. Accessed May 24, 2013.

3. Centers for Medicare and Medicaid Services. Readmissions Reduction Program. Available at: http://www.cms.gov/Medicare/Medicare-Feefor-Service-Payment/AcuteInpatientPPS/Readmissions-Reduction-Program. html. Accessed February 25, 2014.

4. Joynt K, Jha A. A path forward on Medicare readmissions. N Engl J Med. 2013;368:1175-1177.

5. Arbaje AI, Wolff JL, Yu Q, Powe NR, Anderson GF, Boult C. Postdischarge environmental and socioeconomic factors and the likelihood of early hospital readmission among community-dwelling Medicare beneficiaries. Gerontologist. 2008;48:495-504.

6. Congressional Budget Office. Table 1. CBO's May 2013 Estimate of the Effects of the Affordable Care Act on Health Insurance Coverage. Available at: http://www.cbo.gov/sites/default/files/cbofiles/attach ments/43900-2014-04-ACAtables2.pdf. Accessed September 24, 2013.

7. Newhouse JP. Insurance Experiment Group. Free for All? Lessons from the RAND Health Insurance Experiment. Cambridge, MA: Harvard University Press; 1993.

8. Finklstein A, Taubman S, Wright B, et al. The Oregon health insurance experiment: evidence from the first year. Q J Econ 2012;127(3): 1057-1106. 
9. Long S. On the road to universal coverage: impacts of reform in Massachusetts at one year. Health Affairs 2008;27(4):w270-w284.

10. Kaiser Family Foundation. Key facts about the uninsured population. Available at: http://kff.org/uninsured/fact-sheet/key-facts-about-theuninsured-population. Accessed April 15, 2014.

11. Chen C, Scheffler G, Chandra A. Massachusetts' health care reform and emergency department utilization. N Engl J Med. 2011; 365:e25.

12. Commonwealth of Massachusetts, Center for Health Information and Analysis. Massachusetts acute hospital financial performance: fiscal year 2012. Available at: http://www.mass.gov/chia/docs/r/pubs/13/ acute-hospital-financial-performance-annual-report-fy12.pdf. Accessed October 12, 2013.

13. Healthcare Cost and Utilization Project. HCUP comorbidity software. Agency for Healthcare Research and Quality, Rockville, MD. Available at: http://www.hcup-us.ahrq.gov/toolssoftware/comorbidity/com orbidity.jsp. Accessed December 15, 2010.

14. Elixhauser A, Steiner C, Harris DR, Coffey RM. Comorbidity measures for use with administrative data. Med Care. 1998;36(1):8-27.

15. Southern DA, Quan H, Ghali WA. Comparison of the Elixhauser and Charlson/Deyo methods of comorbidity measurement in administrative data. Med Care. 2004;42(4):355-360.
16. Li B, Evans D, Faris P, Dean S, Quan H. Risk adjustment performance of Charlson and Elixhauser comorbidities in ICD-9 and ICD-10 administrative databases. BMC Health Serv Res. 2008;8:12.

17. Mukamel DB, Glance LG, Dick AW, Osler TM. Measuring quality for public reporting of health provider quality: making it meaningful to patients. Am J Public Health. 2010;100(2):264-269.

18. Goodnough A. Massachusetts in suit over cost of universal care. New York Times. July 16, 2009:A16. Available at: http://www.nytimes. com/2009/07/16/us/16hospital.html?_r=0. Accessed November 20, 2013.

19. Rudowitz R. How do Medicaid Disproportionate Share Hospital (DSH) payments change under the ACA? Kaiser Family Foundation, November 18, 2013. Available at: http://kff.org/medicaid/issue-brief/ how-do-medicaid-disproportionate-share-hospital-dsh-payments-changeunder-the-aca. Accessed December 20, 2013.

20. Massachusetts Division of Health Care Finance and Policy. Inpatient hospital discharge database documentation manual. Available at: http://www.mass.gov/chia/docs/r/hdd/hdd-manual-2009.pdf. Accessed March 13, 2014.

21. National Quality Forum. Endorsement summary: all-cause readmissions. April 2012. Available at: http://www.qualityforum.org. Accessed November 15, 2013. 